\title{
ANALISIS PENGARUH PIUTANG, KECUKUPAN MODAL DAN \\ KAS TERHADAP PROFITABILITAS BANK PEMBIAYAAN \\ RAKYAT SYARIAH (BPRS) DI SUMATERA BARAT
}

\author{
Syukri Iska \\ IAIN Batusangkar Sumatera Barat \\ syukriiska@iainbatusangkar.ac.id \\ Fitriani \\ BRI Cabang Batusangkar, Sumatera Barat \\ fitriani_8912@yahoo.com
}

\begin{abstract}
ABSTRAK
Penelitian ini bertujuan untuk menguji pengaruh piutang, kecukupan modal, dan kas terhadap profitabilitas pada BPRS Sumatera Barat. Jenis penelitian yang gunakan untuk mendapatkan data-data dari permasalahan yang diteliti adalah penelitian Expost Facto. Datanya berbentuk sekunder tahun 2011-2017, yang diperoleh melalui website OJK. Pengelolaan data dilakukan dengan pendekatan kuantitatif. Dari penelitian dapat disimpulkan bahwa secara parsial piutang dan kas tidak berpengaruh signifikan terhadap profitabilitas. Namun kecukupan modal berpengaruh signifikan terhadap profitabilitas. Secara simultan piutang, kecukupan modal dan kas berpengaruh signifikan terhadap profitabilitas. Untuk mencapai peningkatan profit BPRS harus mempunyai tingkat piutang, kecukupan modal dan kas yang bagus di mana masingmasing variabel diproksikan dengan rasio FDR, CAR, cash ratio.

Kata Kunci: Piutang, Kecukupan Modal, Kas dan Profitabilitas
\end{abstract}

\begin{abstract}
This study aims to examine the effect of accounts receivable, capital adequacy, and cash on profitability at BPRS West Sumatra. This type of research that is used to obtain data from the problems studied is the Expost Facto research. The data is in the secondary form in 2011-2017, obtained through the OJK website. Data management is done with a quantitative approach. From the research it can be concluded that partially receivables and cash have no significant effect on profitability. But capital adequacy has a significant effect on profitability. Simultaneously receivables, capital adequacy and cash have a significant effect on profitability. To achieve an increase in profit the BPRS must have a good level of receivables, capital adequacy and cash in which each variable is proxied by a ratio of FDR, CAR, cash ratio.

Keywords: Credit, Capital Adequacy, Cash and Profitability
\end{abstract}

Iltizam Journal Of Shariah Economic Research, Vol. 4, No. 1, 2020

Fakultas Ekonomi dan Bisnis Islam UIN Sulthan Thaha Saifuddin Jambi

E-ISSN: 2598-2540, P-ISSN: 2598-2222 


\section{PENDAHULUAN}

Bank Pembiayaan Rakyat Syariah (BPRS) merupakan salah satu bentuk lembaga keuangan bank, di samping Bank Umum Syariah, yang dikelola berdasarkan prinsip syariah. Kalau Kamal Khir dkk. ${ }^{1}$ mendefinisikannya sebagai bank yang beroperasi dengan tidak tergantung dengan bunga melainkan bagi hasil. Dalam ungkapan lain Ahmed, $Z^{2}$ menyatakan sebagai lembaga keuangan yang selaras dengan system nilai dan etos Islam.. Atau lebih jelas lagi, pengelolaan bank yang didasarkan pada Alquran, Sunnah Nabi, dan kaidah-kaidah fikih. ${ }^{3}$

Pada dasarnya, semua institusi baik yang berbentuk badan usaha komersial ataupun lembaga-lembaga sosial kemasyarakatan, tentu mempunyai suatu tujuan dan motivasi yang bervariasi, sesuai dengan identitas masing-masing lembaga tersebut. Tapi, setidaknya, lembaga komersial apapun dianya, baik industry barang dan jasa, maupun perniagaan, tidak terkecuali industry jasa perbankan syariah, tentunya didorong oleh motif untuk mendapatkan keuntungan (profit).

Dalam PBI No: 9/1/PBI/2007 menyebutkan bahwa permodalan dan likuiditas merupakan beberapa faktor yang mempengaruhi kondisi atau kinerja suatu bank. Di sisi lain, melalui rasio likuiditas, pihak manajemen dapat memantau ketersediaan jumlah kas khususnya dalam kaitannya dengan pemenuhan kewajiban yang akan segera jatuh tempo. ${ }^{4}$

Muhammad $^{5}$ menjelaskan bahwa bank yang memiliki tingkat kecukupan modal yang baik menunjukkan indikator sebagai bank yang sehat. Sebab kecukupan modal bank menunjukkan keadaannya yang dinyatakan dengan

\footnotetext{
1 Kamal Khir, et.al, (2008), Longman Islamic Banking: a Practical Perspective, Selangor Darul Ehsan: Pearson Malaysia Sdn. Bhd., hlm. 3

2 Ziauddin Ahmed, (1984), Concept and Model of Islamic Banking: an Assesment. Islamabad: Intenational Institute of Islamic Economic, hlm. 5

${ }^{3}$ Abdullah b. Muhammad b. Ahmad al-Tayyar, (1414 H), al-Bunuk al-Islamiyyah Baina al-Muzariyyah wa al-Tathbiq: Riyad: Dar Wathn, hlm. 88.

${ }^{4}$ Hery, (2015), Analisis Kenerja Manajemen, Jakarta: PT. Grasindo, hlm. 157.

${ }^{5}$ Muhammad, (2004), Manajemen Dana Bank Syariah, Yogyakarta: Ekonisia, hlm. 106.
} 
suatu ratio tertentu yang disebut ratio kecukupan modal atau Capital Adequacy Ratio (CAR).

Beberapa tujuan dari manajemen dana di perbankan, tidak terkecuali Bank Syariah, bahwa untuk memperoleh profit yang optimal adalah menyediakan aktiva cair dan kas yang memadai. Untuk melihat keadaan bank yang baik dalam memelihara tersedianya aktiva cair dan kas ini, dinyatakan dengan suatu ratio yang disebut dengan rasio kas (Cash Ratio), yaitu suatu likuiditas minimum yang wajib dipelihara oleh setiap bank dan terpenuhi kebutuhan masyarakat akan pembiayaan. ${ }^{6}$ Untuk menunjukkan kesehatan bank dalam memberikan pembiayaan atau menghasilkan piutang dapat dinyatakan dengan rasio yang disebut Financing Deposit Ratio (FDR).?

Berdasarkan data yang diperoleh dari website OJK tentang perkembangan BPRS Sumbar dari tahun 2011 ke tahun 2017, tergambar bahwa total asset dan DPK BPRS dari tahun ketahun meningkat, yang menggambarkan bahwa kas yang tersedia untuk memenuhi kewajiban segera meningkat dari tahun ke tahun. Pembiayaan yang disalurkan BPRS Sumbar dari tahun ke tahun juga mengalami peningkatan, diikuti oleh modal kerja BPRS yang tersedia cenderung meningkat dari tahun ke tahun. Namun rasio Return on Asset (ROA) sebagai pengukuran terhadap profitabilias, yang tergambar bahwa BPRS Sumbar menghasilkan profitabilitas dari keseluruhan aktiva yang dimiliki dari tahun ke tahun cenderung mengalami penurunan. Artinya terlihat bahwa meningkatnya total aset, DPK, pembiayaan dan modal kerja yang diperoleh BPRS, tidak berbanding lurus dengan rasio ROA yang harusnya juga ikut mengalami peningkatan.

Berdasarkan temuan data yang tergambar di atas, maka dilakukan penelitian lebih jauh yang difokuskan tentang pengaruh piutang, kecukupan 99.

${ }^{6}$ Muchdarsyah Sinungan, (1992), Manajemen Dana Bank, Edisi kedua, Jakarta: PT. Bumi Aksara, hlm.

${ }^{7}$ Muhammad, (2004), op-cit, hlm. 107. 
modal dan kas terhadap profitabilitas Bank Pembiayaan Rakyat Syariah yang ada di Sumatera Barat. 


\section{STUDI LITERATUR}

\section{A. Profitabilitas}

Tingkat kemampuan bank dalam mencari keuntungan atau laba dalam periode tertentu disebut profitabilitas. Perusahaan dikatakan memiliki profitabilitas yang baik jika perusahaan dapat mencapai target keuntungan berdasarkan aset yang dimiliki oleh perusahaan tersebut. ${ }^{8}$

Saat ini, peranan bank sangat mendukung kemajuan dalam bidang pembayaran, perdagangan dan pembangunan ekonomi, karena ia berperan untuk mengumpul dana (tabungan) dan menjadi sumber pembayaran modal (kredit) kepada perusahaan. Bank sebagai pihak manajemen pembayaran mendorong kemajuan perdagangan barter kepada perdagangan uang seterusnya kepada perdagangan kredit, sehingga pembangunan ekonomi semakin maju bahkan bank boleh dikatakan sebagai jantung dan pusat perekonomian yang harus dimanfaatkan oleh setiap perusahaan, jika perusahaan ingin maju. ${ }^{9}$

Pramuka ${ }^{10}$ menjelaskan bahwa dalam bisnis perbankan struktur keuangan berpengaruh positif terhadap profitabilitas. Artinya bila debt to equity meningkat maka menunjukkan semakin tinggi dana yang tersedia dan memberikan kesempatan pihak bank untuk mengelolanya berupa peningkatan kredit atau pembiayaan kepada masyarakat yang berarti memberikan peluang untuk peningkatan profitabilitas.

Bisnis perbankan akan berhadapan dengan berbagai jenis resiko kredit ${ }^{11}$, di antaranya adalah: resiko modal (capital risks); resiko pembiayaan (financing risks); resiko likuiditas (liquidity risks); dan resiko operasional (operational risks). Resiko modal (capital risk) yang merefleksikan tingkat leverage yang dipakai oleh bank.

\footnotetext{
${ }^{8}$ Kasmir, (2009), Pengantar Manajemen Keuangan, Jakarta: Kencana, hlm. 117.

${ }^{9}$ Syukri Iska, (2012), Sistem Perbankan Syariah di Indonesia dalam Perspektif Fikih Ekonomi, Yogyakarta: Fajar Media Press, hlm. 16.

${ }^{10}$ Bambang Agus Pramuka, (2010), Faktor-faktor yang Mempengaruhi terhadap Tingkat Profitabilitas Bank Umum Syariah, Jurnal Akuntansi Manajemen Bisnis dan Sektor Publik (JAMBSP), ISSN 1829-9857, Vol. 7 No. 1-Oktober (on Line), Diakses tanggal 9-5-2018.

${ }_{11}$ Muhammad, (2005), Manajemen Bank Syariah, Edisi Revisi, Yogyakarta: UUP AMP YKPN, hlm.358360.
} 
Salah satu fungsi modal adalah melindungi para penyimpan dana terhadap kerugian yang terjadi pada bank. Resiko pembiayaan muncul jika bank tidak bisa memperoleh kembali cicilan dari pinjaman yang diberikannya atau investasi yang sedang dilakukannya. Resiko likuiditas muncul manakala bank mengalami ketidakmampuan untuk memenuhi kebutuhan dana (cash flow) dengan segera, dan dengan biaya yang sesuai, baik untuk memenuhi kebutuhan transaksi sehari-hari maupun untuk memenuhi kebutuhan dana yang mendesak.

Menurut Dendawijaya ${ }^{12}$ untuk manganalisis kinerja keuangan dapat digunakan beberapa analisis rasio, yaitu analisis rasio likuiditas (seperti misalnya dengan cash ratio, reserve requirement, loan to deposit ratio, loan to asset ratio, dan rasio kewajiban bersih call money), analisis rasio rentabilitas (seperti misalnya ROA, ROE (Return on Equity), BOPO (Biaya Operasional terhadap Pendapatan Operasional), dan NPM atau (Net Profit Margin), dan yang terakhir adalah dengan analisis rasio solvabilitas (CAR, Debt to Equity Ratio, dan Long Term Debt to Asset Ratio).

Menurut Hery $^{13}$ hasil pengembalian atas aset merupakan rasio yang menunjukkan seberapa besar kontribusi aset dalam menciptakan laba bersih. Dengan kata lain, rasio ini digunakan untuk mengukur seberapa besar jumlah laba bersih yang akan dihasilkan dari setiap rupiah dana yang tertanam dalam total aset. Semakin tinggi hasil pengembalian atas aset berarti semakin tinggi pula jumlah laba bersih yang dihasilkan dari setiap rupiah dana yang tertanam dalam total aset. Sebaliknya, semakin rendah hasil pengembalian atas aset berarti semakin rendah pula jumlah laba bersih yang dihasilkan dari setiap dana yang tertanam dalam total aset.

\section{B. Piutang}

\footnotetext{
${ }^{12}$ Lukman Dendawijaya, (2009), Manajemen Perbankan, Jakarta: Ghalia Indonesia, hlm. 18.

${ }^{13}$ Hery, op-cit, hlm. 193.
} 
Piutang adalah tagihan yang timbul dari transaksi jual beli. Piutang pada perbankan adalah tagihan dari pihak ketiga yang terjadi karena adanya transaksi. Piutang pada penelitian ini merupakan pembiayaan yang diberikan pada pihak ketiga oleh BPRS baik menggunakan akad Mudharabah, Musyarakah, Murabahah, Salam, Istishna;, Ijarah, dan Qardh. Piutang yang dihasilkan atau pembiyaan yang diberikan dalam perbankan syariah dikenal dengan istilah teknisnya aktiva produktif, yang menurut ketentuan Bank Indonesia merupakan penanaman dana Bank Syariah baik dalam rupiah maupan valuta asing ${ }^{14}$

Di perbankan piutang tersebut merupakan pembiayaan yang diukur tingkat pengembaliannya dengan rasio, rasio yang digunakan adalah rasio FDR. FDR (Financing to Deposit Ratio) adalah rasio pembiayaan bank syariah dengan dana pihak ketiga; rasio penyaluran dan penghimpunan dana ${ }^{15}$. FDR merupakan salah satu indikator kesehatan likuiditas bank. Penilaian likuiditas merupakan penilaian terhadap kemampuan bank untuk memelihara tingkat likuiditas yang memadai dan kecukupan manajemen resiko likuiditas. Semakin besar jumlah pembiayaan yang disalurkan oleh bank maka akan semakin rendah tingkat likuiditas bank yang bersangkutan, namun di lain pihak, semakin besar jumlah pembiayaan yang diberikan, diharapkan bank akan mendapatkan return yang tinggi pula. ${ }^{16}$ PBI No.6/9/PBI/2004 menetapkan standar FDR sebesar 85\% - 110\%.

\section{Kecukupan Modal}

Muhammad $^{17}$ menjelaskan bahwa masalah kecukupan modal merupakan hal penting dalam bisnis perbankan. Bank yang memiliki tingkat kecukupan modal baik menunjukkan indikator sebagai bank yang sehat. Sebab kecukupan

\footnotetext{
${ }^{14}$ Muhammad, (2004), op-cit. hlm. 196

15 Wangsawidjaya, (2012), Pembiayaan Bank Syariah, Jakarta: Gramedia Pustaka Utama, hlm. 117.

16 Loc-cit.

${ }^{17}$ Muhammad, (2004), op-cit, hlm. 106
} 
modal bank menunjukkan keadaanya yang dinyatakan dengan suatu rasio tertentu yang disebut rasio kecukupan modal atau Capital Adequacy Ratio (CAR).

Menurut Wangsawidjaja ${ }^{18}$ Capital Adequacy Ratio (CAR) adalah modal berbanding aktiva yang mengandung resiko atau rasio kecukupan modal minimum dengan memperhitungkan resiko pasar (market risk). CAR menunjukkan seberapa besar modal bank untuk menunjang kebutuhannya. Jika semakin besar CAR maka akan semakin besar daya tahan bank yang bersangkutan dan menunjukkan semakin sehat bank tersebut.

\section{Kas}

Kas adalah alat pembayaran yang siap dan bebas dipergunakan untuk membiayai kegiatan umum perusahaan ${ }^{19}$. Pendapat lain menurut Sartono ${ }^{20}$ kas merupakan seluruh uang tunai yang ada di tangan (cash on hand) dan dana disimpan di bank dalam berbagai bentuk seperti deposito, rekening koran. Kas merupakan alat tukar yang memungkinkan manajemen menjalankan berbagai kegiatan usahanya. Bahkan tidak jarang bahwa dalam kenyataan, keberhasilan perusahaan untuk mempertahankan kelangsungan usahanya tergantung pada kemampuan menyediakan kas untuk memenuhi kewajiban finansial tepat pada waktunya.

Cash Ratio, menurut Nurcahyani, dkk., merupakan kemampuan bank untuk membayar utang lancar dengan menggunakan aset lancar. Cash Ratio merupakan rasio untuk mengukur kemampuan bank melunasi kewajiban yang harus segera dibayar dengan harta likuid yang dimiliki bank tersebut. Sehingga rasio ini digunakan untuk mengukur kemapuan bank dalam membayar kembali simpanan nasabah pada saat ditarik dengan menggunakan alat likuid

\footnotetext{
18 Wangsawidjaya, op-cit, hlm. 116.

${ }^{19}$ Agoes, S., (2012), Auditing, Jakarta: Salemba Empat, hlm. 66.

${ }^{20}$ Sartono, A., (2014), Manajemen Keuangan: Teori dan Aplikasi, Edisi Keempat, Yogyakarta: BPEF, hlm. 415.
} 
yang dimilikinya. Semakin tinggi rasio ini semakin tinggi pula kemampuan likuiditas bank yang bersangkutan. Alat likuid di sini kas serta penanaman dana pada bank lain (antar bank aktiva), sedangkan hutang lancar di sini terdiri dari kewajiban segera, tabungan masyarakat dan deposito masyarakat.

\section{METODE PENELITIAN}

Jenis penelitian ini adalah expost facto. Penelitian expost facto berusaha mencari hubungan sebab akibat dari suatu peristiwa dengan menggunakan pendekatan metode kuantitatif. Penelitian ini menguji dan menganalisis pengaruh langsung antara pengaruh piutang (FDR), kecukupan modal (CAR), dan kas (cash ratio) terhadap profitabilitas (ROA) pada BPRS Sumatera Barat. Penelitian ini dilakukan pada BPRS Sumatera Barat dengan mengambil data website OJK (ojk.go.id) dengan subjek penelitian BPRS Sumatera Barat dengan data laporan keuangan akhir tahun 2011 sampai tahun 2017.

Populasi dalam penelitian ini adalah semua BRPS yang ada di Sumatera Barat yang berjumlah 7 BPRS. Dalam penelitian ini menetapkan total sampling, yaitu menjadikan semua anggota populasi sebagai sampel. Dalam penelitian ini yang dijadikan sampel yaitu sebanyak 7 BPRS yang ada di Sumatera Barat.

Data yang digunakan berupa data sekunder, yaitu data berupa laporan keuangan BPRS yang ada di Sumatera Barat yang didapat dari website resmi OJK dengan alamat website ojk.go.id. Dalam pengumpulan data untuk penelitian ini penulis menggunakan teknik dokumentasi, yaitu dengan cara pengumpulan data website OJK dan melakukan pencatatan secara cermat dari website tersebut. Untuk mendukung keperluan menganalisa data yaitu berupa laporan keuangan BPRS di Sumatera Barat yang penulis dapatkan dari data yang berasal dari website Otoritas Jasa Keuangan (OJK). Penelitian ini bertujuan untuk menguji hipotesis, yaitu pengaruh variabel independen yang terdiri dari piutang, kecukupan modal dan kas terhadap variabel dependen 
yaitu profitabilitas dalam hal ini ROA. Data dianalisis secara kuantitatif dengan menggunakan regresi linier berganda dan uji hipotesis dengan bantuan program SPSS versi 22.

\section{HASIL PENELITIAN DAN PEMBAHASAN}

Pengujian hipotesis dilakukan dengan menggunakan uji statistik dengan mempertimbangkan hasil persamaan regresi berganda yang ditetapkan di atas, meliputi:

\section{A. T-test (Uji Parsial)}

Dalam uji-t terdapat ketentuan yang menyatakan variabel independen berpengaruh secara signifikan terhadap variabel dependen yaitu apabila thitung $>$ ttabel maka dapat dikatakan ada pengaruh antara variabel independen dengan variabel dependen dan sebaliknya. Kemudian untuk menentukan apakah pengaruh tersebut signifikan uji t memiliki nilai koefisien signifikansi yaitu jika $\mathrm{t}<0.05$ maka baru bisa dikatakan adanya pengaruh yang signifikan antara variabel independen dengan variabel dependen.

Hasil perhitungan analisis transformasi guna menguji hipotesis-hipotesis yang diajukan dapat dilihat pada tabel sebagai berikut: 
Tabel

Hasil Uji T

Coefficients $^{\mathrm{a}}$

\begin{tabular}{|c|c|c|c|c|c|c|}
\hline \multirow{2}{*}{\multicolumn{2}{|c|}{ Model }} & \multicolumn{2}{|c|}{$\begin{array}{c}\text { Unstandardized } \\
\text { Coefficients }\end{array}$} & \multirow{2}{*}{$\begin{array}{c}\begin{array}{c}\text { Standardiz } \\
\text { ed } \\
\text { Coefficient } \\
\text { s }\end{array} \\
\\
\text { Beta }\end{array}$} & \multirow[b]{2}{*}{$\mathrm{t}$} & \multirow[b]{2}{*}{ Sig. } \\
\hline & & B & $\begin{array}{l}\text { Std. } \\
\text { Error }\end{array}$ & & & \\
\hline \multirow[t]{4}{*}{$\overline{1}$} & $\begin{array}{l}\text { (Consta } \\
\text { nt) }\end{array}$ & .384 & 1.217 & & .315 & .754 \\
\hline & $\begin{array}{l}\mathrm{LOG}_{-} \\
\mathrm{X} 1\end{array}$ & -.630 & .563 & -.162 & -1.118 & .271 \\
\hline & $\begin{array}{l}\mathrm{LOG}_{-} \\
\mathrm{X} 2\end{array}$ & .967 & .322 & .441 & 3.000 & .005 \\
\hline & $\begin{array}{l}\mathrm{LOG}_{-} \\
\mathrm{X} 3\end{array}$ & -.116 & .251 & -.068 & -.462 & .647 \\
\hline
\end{tabular}

a. Dependent Variable: LOG_Y

Sumber: data diolah 2018

Besarnya angka t-tabel dengan ketentuan $\alpha=0,05$ sehingga diperoleh nilai t-tabel sebesar 2,014. Berdasarkan tabel di atas, maka dapat diketahui pengaruh masing-masing variabel sebagai berikut:

1. Variabel FDR terhadap ROA

Dari tabel coefficients diperoleh nilai $\mathrm{t}$-hitung $=-1,118$ yang artinya $\mathrm{t}$-hitung $<\mathrm{t}-$ tabel $(-1,118<2,014)$ dengan signifikansi $0,271>0,05$. Sehingga Ho diterima dan Ha ditolak artinya secara parsial tidak dapat pengaruh FDR (piutang) secara signifikan terhadap ROA (profitabilitas).

\section{Variabel CAR terhadap ROA}

Dari tabel coefficients diperoleh nilai t-hitung $=3,000$ yang artinya t-hitung $>\mathrm{t}$ tabel $(3,000>2,014)$ dengan signifikansi $0,005<0,05$ maka Ho ditolak dan Ha diterima sebab thitung $>$ ttabel dan sig $\mathrm{t}<\alpha$ sehingga dapat disimpulkan 
bahwa rasio CAR (kecukupan modal) berpengaruh positif dan signifikan terhadap profitabilitas (ROA).

3. Variabel Cash Ratio terhadap ROA

Dari tabel coefficients diperoleh nilai $\mathrm{t}$-hitung $=-0,462$ yang artinya $\mathrm{t}$-hitung $<\mathrm{t}$ tabel $(-0,462<2,014)$ dengan signifikansi 0,647 > 0,05 maka Ho diterima dan Ha ditolak artinya secara parsial tidak terdapat pengaruh signifikan kas likuid (cash ratio) terhadap ROA (profitabilitas).

\section{B.Uji F (Uji Simultan)}

Uji statistik F pada dasarnya menunjukkan apakah semua variabel independent yang dimasukkan dalam model mempunyai pengaruh secara bersama-sama terhadap variabel dependent-nya. Untuk melihat tingkat simultan ini dapat dilakukan dengan membandingkan f-hitung > f-tabel. Jika f-hitung > f-tabel, maka terdapat pengaruh antara variabel independen dengan variabel dependen dan sebaliknya. Sedangkan untuk nilai koefisien $f$ simultan ini dikatakan signifikan jika $\mathrm{f}<5 \%$. Namun jika $\mathrm{f}>5 \%$ berarti tidak ada pengaruh yang signifikan antara variabel independen dengan variabel dependen. Hasil perhitungan Uji F ini dapat dilihat pada Tabel berikut ini:

\section{Tabel}

Hasil Uji F

ANOVA $^{\mathrm{a}}$

\begin{tabular}{|c|c|c|c|c|c|}
\hline Model & $\begin{array}{l}\text { Sum of } \\
\text { Squares }\end{array}$ & df & $\begin{array}{l}\text { Mean } \\
\text { Square }\end{array}$ & $\mathrm{F}$ & Sig. \\
\hline $\begin{array}{l}\text { Regressi } \\
\text { on }\end{array}$ & 592 & 3 & \multirow{3}{*}{$\begin{array}{c}197 \\
.058\end{array}$} & \multirow[t]{3}{*}{3.400} & \multirow[t]{3}{*}{$.027^{b}$} \\
\hline Residual & 2.206 & 38 & & & \\
\hline Total & 2.798 & 41 & & & \\
\hline
\end{tabular}

a. Dependent Variable: LOG_Y

b. Predictors: (Constant), LOG_X3, LOG_X1,LOG_X2

Sumber: data diolah 2018 
Jika f-hitung $>$ f-tabel maka Ho ditolak dan Ha diterima, dan sebaliknya jika fhitung $<$ f-tabel maka Ho diterima dan Ha ditolak. Dari tabel di atas diperoleh f-hitung sebesar 3,400 dan f-tabel sebesar 2,79. Berarti f-hitung $>$ f-tabel, sehingga Ho ditolak dan Ha diterima dengan signifikansi 0,027 $<0,05(\operatorname{sig} \mathrm{t}<$ $\alpha$ ). Untuk itu dapat diartikan bahwa secara bersama-sama terdapat pengaruh positif dan signifikan antara variabel piutang (FDR), kecukupan modal (CAR) dan kas (Cash Ratio) terhadap profitabilitas (ROA).

\section{PENUTUP}

\section{A. Kesimpulan}

Dari hasil penelitian ini didapat bahwa secara parsial tidak terdapat pengaruh antara piutang (FDR) dan Kas (Cash Ratio) terhadap profitabilitas (ROA), karena hasil signifikansi lebih besar dari pada 0,05. Sedangkan dari sisi kecukupan modal mempunyai pengaruh yang signifikan terhadap profitabilitas pada BPRS Sumatera Barat, karena hasil nilai signifikansi lebih kecil dari 0,05. Hal ini mengandung implikasi bahwa BPRS Sumatera Barat harus meningkatkan kecukupan modal agar mendapatkan tingkat profitabilitas yang lebih baik. Dengan memiliki modal yang cukup dapat menutup risiko kerugian dan melakukan hapus buku akibat penurunan kualitas aktiva, serta BPRS telah optimal dalam hal memanfaatkan modal yang tersedia.

Secara simultan dari penelitian ini menghasilkan bahwa piutang, kecukupan modal dan kas memiliki pengaruh yang signifikan terhadap profitabilitas. Hasil ini juga ditunjukkan dengan nilai signifikanasi lebih kecil dari 0,05. Hal ini mengandung implikasi bahwa BPRS Sumatera Barat harus memperhatikan dan meningkatkan tingkat piutang, kecukupan modal dan kas secara bersamaan agar mendapatkan tingkat profitabilitas yang lebih tinggi.

\section{B. Saran}


Berdasarkan hasil penelitian yang telah dilakukan dan kesimpulan di atas, maka beberapa saran yang dapat disampaikan adalah:

1. Bagi Bank Pembiayaan Rakyat Syariah (BPRS) terus memantau kinerja keuangannya dengan memperhatikan rasio-rasio keuangan perbankan yang berpengaruh terhadap profitabilitas seperti variabel dalam penelitian ini maupun variabel yang di luar penelitian ini. Sehingga BPRS diharapkan terus meningkatkan efisiensi operasionalnya agar dapat meningkatkan keuntungan.

2. Bagi peneliti selanjutnya diharapkan menggunakan penambahan variabel lain di luar variabel dalam penelitian ini, seperti variabel NPF, BOPO, biaya operasional, tingkat inflasi, tingkat suku bunga BI, jumlah uang yang beredar dan penguasaan pasar. 


\section{DAFTAR PUSTAKA}

Ahmed, Ziauddin, (1984), Concept and Model of Islamic Banking: an Assesment. Islamabad: Intenational Institute of Islamic Economic.

Agoes, S. (2012). Auditing, Jakarta: Salemba Empat.

Dendawijaya, Lukman. (2009). Manajemen Perbankan. Jakarta: Ghalia Indonesia. Hery. (2015). Analisis Kinerja Manajemen. Jakarta: PT. Grasindo.

Iska.Syukri. (2012). Sistem Perbankan Syariah di Indonesia dalam Perspektif Fikih Ekonomi. Yogyakarta: Fajar Media Press.

Kasmir. (2009). Pengantar Manajemen Keuangan. Edisi I, Cet. Ke-1. Jakarta: Kencana.

Khir, Kamal, et.al, (2008), Longman Islamic Banking: a Practical Perspective, Selangor Darul Ehsan: Pearson Malaysia Sdn. Bhd.

Muhammad. (2004). Manajemen Dana Bank Syariah. Yogyakarta: Ekonisia.

Muhammad. (2005). Manajemen Bank Syariah Edisi Revisi. Yogyakarta: UUP AMP YKPN.

Nurcahyani, Risca Fitri, Isharijadi, dan Anggita Langgeng Wijaya. (2017). Analisis Perbedaan Tingkat Likuiditas BPR Konvensional dan BPR Syariah Guna Mengetahui Tingkat Kesehatan Keuangan (Studi pada BPR di Kabupaten Magetan). The $9^{\text {th }}$ FIPA: Forum Ilmiah Pendidikan Akuntansi- Universitas PGRI Madium Vol. 5 No. 1 Hlmn. 167-178 Madium, Oktober 2017 e-ISSN: 2337-9723. (online) http://prosiding.unipma.ac.id/index.php/FIPA/article/view/287, Diakses tanggal 27-2-2018.

PBI No: 9/1/PBI/2007 Tentang Sistem Penilaian Tingkat Kesehatan Bank Perkreditan Rakyat Berdasarkan Prinsip Syariah.

Pramuka, Bambang Agus. (2010). Faktor-faktor yang Mempengaruhi terhadap tingkat Profitabilitas Bank Umum Syariah. Jurnal Akuntansi Manajemen 
Bisnis dan Sektor Publik (JAMBSP), ISSN 1829-9857, Vol.7 No. 1-Oktober. (Online)

https:/ / scholar.google.co.id/scholar?hl=id\&as_sdt=0\%2C5\&q=Faktorfaktor+yang+Mempengaruhi+terhadap+tingkat+Profitabilitas + Bank $+U$ mum + Syariah\&btnG=, Diakses tanggal 9-5-2018.

Sartono, A. (2014). Manajemen Keuangan: Teori dan Aplikasi, Edisi keempat. Yogyakarta: BPEF.

Sinungan, Muchdarsyah. (1992). Manajemen Dana Bank Edisi Kedua. Jakarta: PT. Bumi Aksara.

Susanto, Bambang. (2005). Manajemen Akuntasni, cetakan pertama. Jakarta: Sansu Moto.

Tayyar, al., Abdullah b. Muhammad b. Ahmad, (1414 H), al-Bunuk al-Islamiyyah Baina al-Muzariyyah wa al-Tathbiq: Riyad: Dar Wathn.

Wangsawidjaja. (2012). Pembiayaan Bank Syariah. Jakarta: Gramedia Pustaka Utama. 